\title{
La esquiva y nunca implementada democratización regional en Chile
}

\author{
Esteban Valenzuela Van Treek*
}

\begin{abstract}
Resumen:
El presente artículo busca explicar por qué Chile ha sido tan reticente a la elección democrática con niveles de autonomía del nivel intermedio de gobierno llamado gobierno regional, hoy a cargo de un intendente delegado del Gobierno Central aunque desde el 2014 con un consejo regional electo. Chile es el único caso en las grandes democracias de América Latina, ya que a los tradicionales países federales (México, Argentina, Brasil, Venezuela) y autonomistas (Colombia), desde el 2000 se han sumado a elegir el ejecutivo macro territorial Perú, Paraguay, Ecuador y Bolivia. La razón es la naturalización del modelo "presicrático", de presidencialismo con centralismo, que se remonta a 1830. Finalmente se explica el auge de protestas regionalistas y los proyectos emanados de la Comisión Presidencial para la Descentralización que Bachelet creó el año 2014. También se grafica el modelo dual incremental que se debate en el Congreso y la tensión entre la derecha conservadora y la izquierda centralista que se enfrenta a la centro izquierda que busca profundizar la democracia aliada a la Democracia Cristiana y segmentos liberales.
\end{abstract}

Palabras claves: Chile, descentralización, gradualismo, cooptación, presidencialismo

\section{The avoiding and never implemented regional democratization in Chile}

\begin{abstract}
:
The present article seeks to explain why Chile has been so reticent to the democratic election with levels of autonomy of the intermediate level of government called regional government, today in charge of an intendente delegate of the Central Government although from the 2014 with an elected regional council. Chile is the only case in the great democracies of Latin America, in opossition a traditional democratic power whithin traditional federal countries (Mexico, Argentina, Brazil, Venezuela), Colombia from 1992 and since 2000 have joined to choose the macro territorial executive Peru, Paraguay, Ecuador and Bolivia. The reason is the naturalization of the "presicratic" model of presidentialism with centralism dating back to 1830 . Finally, the paper explains the rise of regionalist protests and the projects emanating from the Presidential Commission for Decentralization that Bachelet created in 2014, generating an incremental dual model that is debated in Congress. Chile lives a tension between the conservative right allied with the centralist left that resist a change of political system against the left center that seeks to deepen democracy allied to Christian Democracy and liberal segments.
\end{abstract}

Key words: Chile, decentralization, gradualism, cooptation, presidentialism

Trabajo enviado: 22/05/2017 Trabajo aceptado: 30/06/2017

\footnotetext{
* Dr. en Historia (Valencia), Máster en Ciencia Política (UC) y en Desarrollo (UW-Madison). Fue alcalde y diputado por Rancagua. Asesor GIZ en desarrollo territorial para América Latina. Presidió Comisión de Estado para la Descentralización (2014). Director del Magíster en Estudios Sociales y Políticos de América Latina de la Universidad Alberto Hurtado. Este trabajo es parte de del proyecto de investigación Movimientos Regionalistas y Ciclo de reformas FONDECYT 1150 684. Tributario de opiniones en El Mostrador, conferencia en el Simposio Chileno-Argentino en el Congreso de la Democracia en Rosario (2016), del texto introductorio del libro "Descentralización Ya"(2015) y del artículo sobre el "El modelo chileno de descentralización dual incremental" publicado por la revista RIEM( Revista Iberoamericana de Estudios Municipales). Correo electrónico: evalenzu@uahurtado.cl
} 
"En Chile el proceso de regionalización ha sido declarativo, formal y burocrático. Las políticas de descentralización, adornadas con un falso discurso regionalista, han constituido en esencia un reforzamiento del centralismo por la vía de la desconcentración administrativa, pero no se han traducido ni en un reconocimiento ni en una transferencia de poder real a las regiones. El Estado Unitario prevaleciente en toda nuestra historia política se ha consolidado como un estado Unitario centralizado y ha bloqueado persistentemente toda posibilidad efectiva de regionalización. Y no existe regionalización si no hay poder regional tanto político, económico como institucional. Caminar en esa dirección es fundamental para el crecimiento y desarrollo del país, pero ello implica transitar desde un Estado centralizado a un Estado Unitario Regionalizado. La actual situación en La Araucanía ha vuelto a poner de relieve, de manera dramática, esta indispensable transformación del Estado" (Alejandro Bell, 2010: 8-9, ex diputado MAPU por Linares. Se radicó sus últimos años de vida en Iquique).

\section{Introducción: Lucha, esperanza y avance gradualista}

En el momento de recopilar textos para este trabajo sobre la esquiva descentralización en Chile (marzo 2017), seguía en duda la materialización de la elección de gobernadores regionales (los intendentes en la tradición chilena), ya que los partidos dominantes buscaban razones para posponerlo para el año 2020. También se encuentra trabado el proceso de traspaso de competencias y el Ejecutivo no cumplió la promesa de enviar una ley de rentas regionales, no obstante, el amplio consenso unánime de la Comisión Presidencial para la Descentralización del año 2014 que nos correspondió presidir. Se buscaba el ABC básico de todo proceso que sacara a Chile del último lugar en la Organización para la Cooperación y el Desarrollo Económico (OCDE) con Turquía como los países más centralistas, y se colocara a la par de las grandes democracias de América Latina que han avanzado en dichos procesos, además de responder a la rabia territorial por los abandonos y despojos en materia de autonomía, programas sustanciales en políticas complejas (transporte, medio ambiente, competitividad) y coparticipación en la renta por recursos naturales. Finalmente hay un preacuerdo para elegir un gobernador regional en fecha incierta, el Gobierno central tendrá su delegado regional (lo dual) para coordinar las poderosas agencias centrales; el traspaso de competencias vendrá después por la vía de demandas desde las regiones y negociación con el gobierno de turno, creándose al menos divisiones nuevas en los gobiernos regionales (industria, social, infraestructura) y potestad de coordinar las áreas metropolitanas. La ley de rentas seguirá siendo una lucha pendiente para un país que cruje por la demanda social por mayor igualdad que han empujado estudiantes, regiones y los movimientos en favor de un sistema previsional solidario. Chile tiene una carga fiscal media baja de un $21 \%$ en el contexto de América Latina, muy por debajo de Brasil, Uruguay y Argentina que tienen un 30\% en promedio (CEPAL, 2016: 45), lo cual se explica por la inexistencia de coparticipación regional en la renta nacional disminuido a pequeñas tasas de casinos y patentes mineras, además de alta exención del predial en lo municipal que alcanza al 80\% de las viviendas (Comisión para la Descentralización 2014, OCDE 2017).

El miedo a soltar poder se impone por los "brokers" que denunció Arturo Valenzuela en su tesis doctoral de 1977: los parlamentarios que "consiguen" fondos para las regiones y nunca crean un poder autónomo fuerte. Ellos son el poder. Particularmente duro para los grupos regionalistas ha sido la resistencia de la Unión democrática Independiente (UDI) en la derecha, la lentitud de la centro izquierda en general, con predominancia del veto del Partido por la Democracia (PPD) del cual se esperaba que fuese el partido de la redistribución del poder. No obstante, aunque se teme a las regiones, ellas llevan tres décadas de hacer bien lo que les toca en lo incremental del modelo (VALENZUELA, 2015). 
Evolución Articulación Nacional-regional-Municipal en Chile 1980-2020 y largo proceso de Regionalización (proyectado)

\begin{tabular}{|c|c|}
\hline Fechas e hitos & Claves \\
\hline $\begin{array}{l}\text { 1980s creación del Fondo Nacional de } \\
\text { Desarrollo Regional (FNDR) por presión del } \\
\text { Banco Interamericano de Desarrollo (BID) a } \\
\text { la dictadura. }\end{array}$ & $\begin{array}{l}\text { Municipios y sectores postulan proyectos } \\
\text { medianos de infraestructura para el desarrollo; } \\
\text { agua potable, sanea-miento, escuelas, caminos } \\
\text { secundarios. }\end{array}$ \\
\hline $\begin{array}{l}\text { 1992s Inversión Regional de Asignación } \\
\text { Regional, con aprobación de los Consejos } \\
\text { Regionales (CORE) creados en } 1992 . \\
\text { Cooperación con Universidades. } \\
\text { Planes Intercomunales. }\end{array}$ & $\begin{array}{l}\text { Se obliga a los sectores a que el CORE } \\
\text { apruebe la Inversión Sectorial de Asignación } \\
\text { Regional y a su vez a que los COREs pacten } \\
\text { con los municipios la Inversión Regional de } \\
\text { Asignación Local. } \\
\text { Se inician convenios de apoyo mutuo con } \\
\text { universidades públicas regionales. } \\
\text { Se gesta planificación intercomunal con poder } \\
\text { de los tres actores: Municipios, CORE y } \\
\text { Ministerio de la Vivienda (MINVU) en buen } \\
\text { balance que minimiza abusos y permite } \\
\text { cooperación. }\end{array}$ \\
\hline $\begin{array}{l}\text { 2000s Convenios de Programación, nuevos } \\
\text { fondos: } 2 \% \text { y Fondos de Innovación para la } \\
\text { Competitividad (FICs) con recursos de } \\
\text { royalties mineros. }\end{array}$ & $\begin{array}{l}\text { Las regiones hacen Convenios de } \\
\text { Programación multianuales con los sectores } \\
\text { más poderosos (salud, Vivienda, Ministerio de } \\
\text { Obras Públicas) para sus apuestas de } \\
\text { desarrollo. También logran gestar proyectos } \\
\text { culturales, seguridad ciudadana y deportivos } \\
\text { en las comunas con el llamado } 2 \% \text { del FNDR. } \\
\text { Gracias al royalty minero se crean los FICs } \\
\text { con asignación del CORE. }\end{array}$ \\
\hline 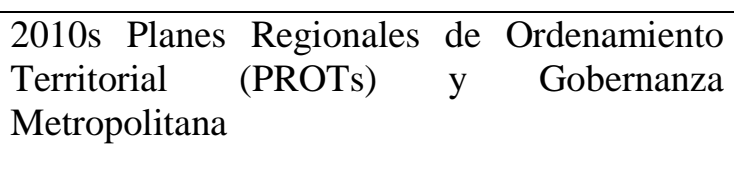 & $\begin{array}{l}\text { Se formalizan los PROTs y se proyecta } \\
\text { Gobernanza en zonas metropolitanas con rol } \\
\text { municipal-regional en transporte, medio } \\
\text { ambiente y basura. }\end{array}$ \\
\hline
\end{tabular}

Fuente. Elaboración propia, marzo 2017.

\section{Una historia de lucha desde 1830 contra la Presicracia}

Tras un fecundo período de búsqueda de democracia, federalismo y Constitución consensuada (1823-1830) se impuso en Chile la coalición conservadora del Ministro Diego Portales naturalizando el centralismo como forma de gobierno en Chile (VALENZUELA, 1999) con municipios básicos (12\% de la recaudación fiscal) y regiones sin autonomía y con un Fondo Nacional de Desarrollo Regional (FNDR) acotado para inversión física que es sólo el 5\% del gasto fiscal. El 84\% de los recursos lo maneja el Gobierno Central y sus agencias (ROSALES, 2012).

Es la historia de lucha de las regiones por la autonomía territorial versus la implacable maquinaria represivo-cooptadora del centralismo chileno. Los conceptos en pugna son el de cooptación - repartición menor de renta sin empoderar, integrando a parte de los críticos a la elite dominante - versus la autonomía que implica elección democrática de representantes, poder político, devolución de recursos económicos significativos por ley - sin discrecionalidad central - y potestades reales de autogobierno en competencias relevantes. Se forma el modelo 
político y la cultura elitista en la clase política de carácter presidencial-centralista que llamamos "presicracia" (VALENZUELA, 2007).

Chile como país profundamente centralista, tiende al estancamiento estructural, económico y también en términos de desarrollo territorial; este retraso tiene otra de sus facetas en el decaimiento en la superación de indicadores básicos tales como: la calidad en la educación - tema por el que el gobierno de turno y sus antecesores han tenido que lidiar irrenunciablemente desde 2006 con la llamada Revolución Pingüina en que los estudiantes de secundaria y universitarios pidieron educación de calidad, gratuita y sin lucro - la superación de la pobreza - con la escases de políticas sociales que se hagan cargo de este problema a nivel rural y regional, centrándose la mayoría de los esfuerzos en la erradicación de campamentos en la Región Metropolitana - la seguridad ciudadana - con un nivel de victimización creciente en Santiago y con muy poca información de las regiones - y la descontaminación de las ciudades - con la puesta en marcha del Transantiago (sistema integrado de transporte metropolitano metro y buses) en 2007, donde se erradican de Santiago los microbuses más contaminantes y son trasladados en su mayoría a continuar con sus labores en regiones, llevando el problema del smog y sus consecuencias para la salud a una zona menos "preponderantes" del país -. Este escenario, no sólo es posible de constatar a nivel social; a nivel político, se da por medio del sistema electoral, el cual garantiza la formación de dos coaliciones casi empatadas que no dan cabida a la emergencia de nuevos actores, además de un presidencialismo sumamente arraigado en el imaginario socio-identitario de la política chilena aferrada a un poder central omnipotente.

A su vez, el desconocimiento de las ideas federalistas y sus beneficios al país, han sido frecuentes en la historia política chilena, basta sólo con recordar las propuestas de José Miguel Infante y su federalismo al estilo estadounidense, el cual no tuvo un buen recibimiento, al punto de asociar este tipo de iniciativas y a los intelectuales de la época con el anarquismo. Desde dicha época emergen opiniones políticas que con el tiempo se hacen creencias populares acerca de lo prejuicioso que podría llegar a ser un modelo descentralizado; se habla además de anarquía, de poco poder estatal, de pérdida de recursos, de fragmentación territorial, secesión, entre otras; mientras que los argumentos se basan en simplismos que aluden a que un país pequeño como Chile no requiere de reformas de este tipo, o que simplemente, la política ni las personas se encuentran preparadas para un cambio de esta índole.

Las razones que se pueden esbozar para defender una lógica federal se pueden dividir en tres grandes temáticas:

a.- Superación del estancamiento económico estructural: La falta de proyectos en regiones y la falta de apoyo que se genera desde Santiago no permiten un buen desarrollo en términos de capitales semilla para iniciativas en lugares más apartados, ni un soporte relevante para el emprendimiento. La ayuda económica a regiones tiende a ser de tipo subsidiario, en el que se garantiza una ayuda parcializada que pretende sólo mejorar la situación ya existente, pero en ningún caso para el fomento de nuevos proyectos que involucren el mejoramiento de las condiciones de vida mediante la innovación.

b.- Dinamización de políticas y programas: El poder central tiene múltiples expresiones en la política que se imparte mediante programas que llegan a todo el país, un claro ejemplo de este tipo de práctica es el Sistema de medición de la Calidad de la Educación (SIMCE), el cual pretende estandarizar la realidad de todos los estudiantes del país, sin importar las diferencias intrínsecas en la enseñanza que pueden adquirir en las distintas latitudes del país. Asimismo, la creación de programas de gobierno, no son aplicables a todas las regiones como tampoco a las culturas que habitan en Chile, entre ellas cabe destacar decisiones que han tenido lugar últimamente en cuanto a la subvención del transporte público durante todo el año para el estudiantado; pero con pleno desconocimiento de los estudiantes de regiones, quienes también tienen las mismas necesidades y actividades que aquellos que se desarrollan en el ámbito santiaguino.

c.- Superación de la crispación política: El modelo actual meramente garantiza la persistencia de los mismos gobernantes y sus gabinetes por un tiempo extenso, con una 
oposición condenada a la crítica de gobierno de turno con muy pocos espacios para el debate y el diálogo político.

La pólvora que alimenta desde el Siglo XIX la agresión centralista a los territorios en Chile, se funda tanto en el presidencialismo autoritario diseñado por Portales, como en el liberalismo del orden que introdujo la visión homogénea de país, permeando a las élites de fetichismo y mentalidad controladora. Así se aplacaron a fuego a los federalistas-regionalistas en 1830, 1848, 1851 y 1859, y luego se colonizó con violencia la Araucanía (1865-1880), despojando a los mapuches de su territorio y de sus derechos políticos. La república oligárquica de derecha (1891-1925) al igual que el período desarrollista dominado por corrientes centroizquierdistas (1938-1973), fortalecieron la concentración del poder económico en Santiago, el municipio mínimo, la negativa a provincias autónomas y la nacionalización homogénea, que folklorizó la representación de lo indígena negándole derechos étnicos y territoriales (MARIMÁN, 2012). Dicho modelo, acentuado por la regionalización autocrática de la dictadura, con sus intendentes militares, y administrada por la Concertación sin reformas; convirtió a Chile en el único país de la OCDE sin democracia regional ni autonomías territoriales, sin devolución significativa de impuestos y recursos a los mismos - entes sub nacionales administran el 14\% de los recursos fiscales versus el $50 \%$ de los países desarrollados - además de ser el único país mediano-grande de América Latina sin elección de autoridades macro territoriales. Nada de autonomía territorial a las etnias - aymaras, rapanuis, atacameños ni pacto político relevante con los mapuches, el pueblo-nación al cual los españoles le reconocieron su territorio al sur del Río Bío-Bío (VALENZUELA, 1999).

La maquinaria dominadora del Gobierno central ha combinado la represión directa contra los territorios rebeldes, con las prácticas cooptadoras: recursos mínimos, comisiones de estudios, prebendas a dirigentes que se cooptan, absorción de los movimientos regionalistas a partidos nacionales, leyes especiales a territorios críticos (zonas extremas), dádivas y micro política integrativas a mapuches y otras etnias.

\section{La rebeldía territorial que pervivió}

Sin embargo, a los aislados fenómenos de la Atacama libre de 1859 (los cuatro meses de emancipación constitucionalista y federal en el norte minero por parte de los liberales "rojos" que formaron el Partido Radical) y el imperio del Partido Regionalista en Magallanes entre 1932-1945, la domesticación de los territorios terminó con el fenómeno de movilización y recuperación del proyecto histórico autonómico de los mapuches. Con sus raíces en la lucha contra la dictadura -Ad Mapu y otras organizaciones -, hacia 1990 se levantan propuestas de región autónoma mapuche, y desde 1995 comienza la toma de bosques y fundos mal habidos por parte de comunidades, lo que desata la creación del Consejo de Toda las Tierras, la Coordinadora Arauco-Malleco, Identidad Lafkenche, entre otras organizaciones que apoyan el rescate étnico, linguiístico, territorial y político. A la palabra autonomía-autodeterminación de los mapuches, hacia el año 2000 segmentos de la élite rescatan la demanda de intendentes elegidos - Los Federales -, y comienza un ciclo de movilizaciones territoriales en demanda de soluciones económicas ante la alta cesantía (Arica, Illapel, Lota-Coronel, Huasco), oposición a mega proyectos eléctricos y mineros que afectan la ecología de las comunidades - desde los pehuenches del Alto Biobío a Pascua Lama -, hasta la irrupción en el bienio 2011-12 de un regionalismo politizado que demanda subsidios, fondos estructurales y poderes (Magallanes, Aysén, Calama).

Conviene remarcar que el grueso de los investigadores toma aspectos parciales y apunta a la construcción de las regiones desde lo social y cultural después de su creación tecnocráticoautoritaria en 1974, lo que venía gestándose acorde con el desarrollismo cepaliano desde 1969 (BOISIER, 1989). Entonces, se confunden los estudios con medidas puntuales de desconcentración, sin analizar el elemento político de tipo de Estado, dominación de los territorios y las trabas puestas a todo elemento democratizador. El sistema político chileno, marcado por su centralismo presidencial muestra una gran capacidad de permanencia desde el triunfo conservador-portaliano (1830) sobre federalistas y "pipiolos liberales", superando 
guerras civiles y protestas regionalistas por la vía del uso de mecanismos de cooptación de dichos disidentes con el poder central.

En Chile, es escasa tanto la historiografía sobre su centralismo como el análisis político de las razones de la cooptación de los movimientos regionalistas, de la fragilidad de estos grupos para crear una coalición interregional (nacional) y de las razones de fondo de la élite del poder para rechazar esta dimensión de la democratización y desarrollo del país. Sobre esa base, nos ha parecido útil aportar algunas claves para indagar de manera novedosa dicha dimensión, combinando el método histórico con una propuesta de análisis político comparado para analizar el "modelo de cooptación", sus fases y su resultado, que podemos definir de antemano como "coalición regionalista débil".

\section{La cooptación de la Presicracia}

Teóricamente se usa el término cooptación, el cual ha ganado terreno en las ciencias políticas e históricas como un concepto más amplio que el mero clientelismo, ya que supone que el Estado secuestra las demandas ciudadanas con dádivas (VON HALDENWANG, 1990), buscando mantener la alianza de grupos estratégicos con la elite dominante (GERSCHEWSKI, 2010). El clientelismo es un vínculo asimétrico con grupos para el aprovechamiento electoral; la cooptación, en cambio, es para evitar transformaciones políticas en una lógica democrática de dispersión del poder, ya que busca evitar rebeliones por la vía de lograr una cooperación cínica basada en concesiones para distribuir parte de la renta (GANDHI, 2006: 2). En el caso chileno, se contrastará la domesticación de las rebeliones regionales y sus movimientos por esta vía centrada en otorgar algunas rentas e integrar al sistema.

El "modelo de cooptación" se repite históricamente, aplaca la demanda regionalista y mantiene un caso excepcional de delegación central en los territorios. Chile, es el único país de la OCDE que no elige sus gobiernos regionales y el único país de tamaño medio-grande sin hacerlo en América: Estados Unidos, Canadá, Brasil, México, Colombia, Argentina y recientemente Perú eligen gobiernos regionales, y tienen más de un $30 \%$ de gasto público descentralizado. Chile, permanece bajo el promedio de América Latina en lo relativo a gasto subnacional, asignando sólo un 14\% (ROSALES, 2012). A ello habría que sumar, además, la dimensión territorial con sus problemas de equidad (MESSNER, 1996). La resistencia a este elemento democrático moderno amerita ahondar en sus lógicas, complejidad y materialización histórica, que es nuestra línea argumental central.

El modelo se reproduce históricamente en la tradición presidencialista del Continente que proyecta elementos monárquicos y populistas, así como la construcción estatal desde arriba (VELIZ, 1984). Sin embargo, desde arreglos federales del siglo XIX como en Argentina, Colombia y Brasil, a nuevas olas democratizadoras-descentralizadoras, América Latina se ha movido hacia la descentralización, con la excepcionalidad chilena donde el autoritarismo se reforzó en la Constitución de 1980 con un presidencialismo exacerbado.

Casi todos los liberales y federalistas que protagonizaron las rebeldías contra el régimen portaliano en 1848 y 1851 tuvieron inspiración en el pensamiento francés y en las ideas del destacado federalista José Miguel Infante. Muchos de los liberales después adhirieron al liberalismo del orden y al nacionalismo homogeneizador que despreció la autonomía provincial y arrasó con los mapuches.

Tras la estabilidad de los decenios conservadores (1830-1860), afectada por la guerra civil contra los alzados de Atacama (1859) que demandaron niveles de autonomía e inversiones por las rentas de la minería (ILLANES, 1992), se establece una suerte de modelo de cooptación que reviste características particulares en tres coyunturas históricas:

a.- La apertura liberal con amnistía a los federalistas y recuperación de los municipios, que inicia el Presidente Pérez tras la Guerra Civil de 1859.

Luego de la derrota federalista y de la tesis de asamblea provincial autónoma de José Miguel Infante (SALAZAR, 2005; VALENZUELA, 2007), se impone el gobierno centralizado 
que suprime la autonomía regional e incluso los municipios, replicando el modelo monárquicoborbónico de la delegación por sobre los espacios de libertad que había construido el Cabildo. La dureza de los decenios conservadores es resistida en el 1848 chileno por los clubes de la igualdad y la libertad, Bilbao y Arcos; para luego irrumpir con fuerza en el levantamiento de 1851 que une a liberales, reformistas y federalistas; incluyendo la participación de nuevas capas sociales - artesanos, pequeños agricultores y profesores- en experiencias como la de San Felipe y la toma de Talca (DAITSMAN, 1995).

Los hechos se agravaron en 1859 con la declaración del Atacama autónomo y Constituyente, el ejército libre el norte, los tormentos públicos dictados por el intendente y el cansancio de los mineros de financiar incluso el tren a Caldera, ante la indolencia y centralismo capitalino (BAHAMONDE, 1977). El gobierno central los aplasta y al menos gana en la élite de poder una figura moderada como Pérez, quien realiza la apertura liberal en el decenio de 1860. Dicha apertura, no repone la Asamblea Provincial Autónoma, pero regresan al menos los municipios y se inician reformas políticas de mayor libertad de prensa y reunión, incluyendo la Ley de Amnistía para los cabecillas Pedro León Gallo y Manual Antonio Matta, los que se integran al sistema de la mano del Partido Radical, sin cambios de fondo al régimen oligárquico. Los sublevados abdican de la petición de autonomía y se hacen parte del nacionalismo liberal centralista. Los conservadores promueven el municipalismo (ILLANES, 1993) como respuesta Ley Irarrázaval de 1891 -, sin regiones fuertes; en la posterior guerra civil contra Balmaceda: municipalismo y parlamentarismo, sin gobiernos regionales, fue la respuesta hasta 1925.

\section{b.- El desarrollismo industrial de las regiones en el Frente Popular como respuesta a la crisis del Estado oligárquico.}

La crisis del régimen oligárquico de 1924, la dictación de leyes sociales, el auge y caída del alessandrismo y el ibañismo, la depresión mundial agravada con la sustitución del salitre, acompañado de los experimentos socialistas de 1932, concluyen con una salida democráticocentralista e industrialista: el Frente Popular. Dicho frente fue integrado por la alianza del Partido Radical, el Partido Socialista y el Partido Comunista junto con algunos de los grupos contestatarios locales, especialmente líderes regionalistas de Magallanes. En la Enciclopedia Chilena preparada por la Biblioteca Nacional (BN, 1972) se le considera "circunstancial" al Partido Regionalista de Magallanes, organizada sólo en su región y vinculada a otros pequeños partidos que reclamaron descentralización: el federalista y el Agrario. Sus raíces provienen de las protestas de Punta Arenas contra impuestos aduaneros en 1910, que se intensifican en los años 30's, uniéndose al auge socialista de 1932 y los movimientos regionalistas que luego aportan al derrocamiento del Gobierno de Dávila. Sus líderes se dividen, una parte se incorpora al Frente Popular con la fuerte presencia socialista en la zona, y otros se hacen aliados de facciones de la derecha que asumen un discurso pro descentralización, apoyando en 1952 al candidato Arturo Matte.

En la historiografía hay quienes resaltan que el nuevo Frente Popular desde 1938 respondió a la división derechista y al corrimiento a la izquierda del Partido Radical (MOULIAN, 2009), iniciando el tiempo de una república democrático-centralista con políticas sociales, pero con alta centralización (SALAZAR, 2005). La visión regionalista remarca que movimientos como el magallánico empujaron hacia una visión más integral del territorio con inversiones en zonas mineras para industrializar y por políticas hacia zonas extremas (MARTINIC, 1992). Es así como vendrá un ciclo de mayor inversión pública y polos de desarrollo - como el acerero en Concepción -, pero sin fondos autónomos ni puesta en funciones de la "asamblea provincial" establecida en la Constitución de 1925, pero nunca reglamentada.

El Frente Popular de 1938 a 1946 empujó la industrialización en el sur del país, especialmente el área de Concepción con siderúrgica, industria textil y metalmecánica, en línea con el desarrollismo y la sustitución de importaciones. Luego el radical González Videla se centró exclusivamente en el Plan Serena para su región natal, siendo reemplazado por el ex dictador Carlos Ibáñez del Campo (1952-58), el cual, con su visión geopolítica, invirtió en las regiones de Aysén y Magallanes, así como en una base Antártica. Al final de su mandato (1957) por el empuje de la Confederación de Trabajadores del Cobre, Ibáñez aceptó la ley que creó un 
Fondo de Desarrollo en las Provincias Mineras ${ }^{1}$ financiado por el 5\% de las ventas brutas de cobre, el cual hasta 1974 fue el único caso relevante de coparticipación territorial en Chile de la renta por recursos naturales.

Bajo el período revolucionario de Frei y Allende (1964-73) se mantuvo el modelo centralizado en lo político, pero con polos industriales en el norte y sur, destacando las corporaciones de desarrollo con puertos libres de Arica y Punta Arenas (VALENZUELA 1999).

La izquierda se hace estatista y no valora la dispersión del poder; más bien recela de la descentralización como un instrumento oligárquico al servicio de latifundistas que con clientelismo controlan municipios. No obstante, los parlamentarios de centro (radicales y demócratas cristianos) al igual que muchos izquierdistas, replican las prácticas liberalesconservadoras de "gestionar proyectos" para "sus comunidades", sin visión de descentralizar y crear fondos autónomos. Se instaura el moderno parlamentario como el "brokers" del poder que lleva las demandas de sus territorios a Santiago (VALENZUELA, 1977).

c.- Los años noventa como período de democratización con una tenue descentralización que comienza a ser exigida en el año 2000

La transición chilena mantuvo el grueso de la política económica con mayor inversión social y disminución de la pobreza, pero pobre en reformas estructurales y mínimo en reforma política, proyectando el duro sistema presidencialista centralista de la constitución pinochetista (VALENZUELA, 2007).

En 1992 con Patricio Aylwin se permitió las elecciones municipales y se crearon los consejos regionales electos por asambleas provinciales de concejales municipales. Se dotó de mayor personal técnico a los Gobiernos Regionales (GOREs) pero se mantuvo la delegación central y la designación de los intendentes regionales. En el gobierno de Frei Ruiz Tagle, se crearon los convenios de programación por los cuales las regiones pactan inversiones plurianuales con los poderosos ministerios centrales sectoriales que dominan la inversión (Obras Públicas, Vivienda, Salud, Educación).

A comienzos del nuevo siglo se constituye el grupo Los Federales, rescatando la versión autonomista del regionalismo, el cual politiza los movimientos regionalistas y académicos provincianos con la demanda de elección de autoridades (MARTELLI et al., 2002). A su vez, durante toda la segunda década de gobiernos de la Concertación, y durante los dos primeros años del Gobierno de Piñera - Alianza - se suceden protestas regionalistas demandando ser región (Arica y Valdivia), regalías por sus recursos (Antofagasta-Calama), planes ante la pobreza y cesantía (Zona del Carbón, Atacama, Illapel), subsidios a los altos costos de energía y transporte en zonas extremas (Magallanes, Aysén).

La Concertación no logra realizar reformas electorales por el rechazo de la derecha bajo un marco constitucional de alto quórum para leyes orgánicas. Tampoco realiza reformas descentralizadoras, en este caso porque la centro izquierda es dominada por una lógica de controlar el aparato estatal con sello paternalista y de distribución de cuotas de poder, asumiendo el modelo presicrático del constitucionalismo pinochetista. Por su parte, en la derecha se percibe una división entre la UDI, que defiende el modelo de delegación en las regiones y reduce la descentralización al municipalismo, y segmentos de Renovación Nacional que propician reformas políticas y proponen con la Democracia Cristiana en el año de las protestas estudiantiles -2011-, la mayor reforma política en medio siglo: semipresidencialismo con poder parlamentario y elección de gobiernos regionales. Estos dos elementos -protestas regionales y propuestas descentralizadoras desde las élites- son claves a la hora de denominar a esta coyuntura como el "retorno del regionalismo".

El cambio lo produce Michelle Bachelet al asumir el ciclo de protestas y tras la Comisión para la Descentralización del 2014, propone un modelo de descentralización dual incremental enviando tras 185 años un proyecto de elección de gobernadores regionales, un

\footnotetext{
${ }^{1}$ Chile hasta 1974 se dividía en 25 provincias, entonces la dictadura regionalizó en trece regiones que hoy llegan a 16 con las nuevas de Arica, Los Ríos (Valdivía) y la ya aprobada Ñuble (Chillán).
} 
sistema de traspaso de competencias que le otorga algunas atribuciones nuevas a los gobiernos regionales en asuntos metropolitanos y de fomento productivo (sin traspasar servicios nacionales), además de prometer una ley de rentas regionales que será debatida a contar del $2018^{2}$.

\section{Un modelo chileno de cooptación y de fragilidad de la alianza regionalizadora-descentralizadora}

La homogeneidad social y económica de la élite chilena es evidente en numerosos estudios, siendo predominantemente funcionales-conservadoras hasta disfuncionales-disruptivas (ALCÁNTARA, 2003). Al mirar el fracaso de una alianza transformadora-regionalizadora en la historia de Chile, se observa que existe una élite centralista que ha dominado la historia del país y debilitado los frentes regionalistas, respondiendo a las crisis con aperturas tibias, repartición de alguna renta y cooptación de líderes. Para analizar esta realidad, se pueden usar desde los clásicos Michels, Mosca y Pareto, pasando por Wright Mills quien remarca que la élite de poder refiere a un grupo que se diversifica, pero mantiene su cohesión en base a sus intereses y creencias fuertes. Dicha definición se plasmaría en el caso chileno, en la idea de que el centralismo construyó su estabilidad y le ha "hecho bien al país".

La elite chilena asentada en los sectores acomodados del Gran Santiago domina e integró a la mayoría de los propios líderes regionalistas (JOIGNANT, 2011), los que generan diversas formas de disidencias, pero finalmente se integran al sistema en un clásico de modelos altamente centralizados y presidencialistas (GAXIE, 1983).

Cabe aclarar, que el carácter homogéneo que exhiben dichas élites es el resultado tanto del origen social-escolar como de las redes de influencia, lo que hace difícil las disrupciones (ALCÁNTARA, 1997; ESPINOZA, 2010). Además, el 90\% vive en barrios acomodados de Santiago y no radica en regiones, convirtiendo lo regional en una parcela electoral y no en una opción vital (BENAVENTE, 2008) con una poderosa red clientelar al estilo priista mexicano (AI CAMP, 2000 y 2003). Así, predominan los llamados "operadores políticos" en la élite chilena quienes están más interesados en la perpetuación del modelo en el cual acumulan poder y distribuyen proyectos, que en dar poder a entes subnacionales colegiados y autónomos.

De lo desarrollado previamente, estamos en condiciones de acuñar el término "convergencia programática de fondo de la élite de poder", para entender la predominancia en Chile de un orden basado en el Estado central, la supervisión, capitalismo con rentas públicas moderadas y control de niveles de autonomía local-regional, el cual se repite en las tres coyunturas históricas. Los elementos del modelo de cooptación centralista se sintetizan en:

a.- La lógica dominadora-cooptadora-centralista se caracteriza por: la represión de los sujetos rebeldes, el llamado nacionalista a la unidad del país, los discursos sobre las ventajas del centralismo en la creación de mínimos para todos los territorios, anuncios de reformas con comisiones de estudios y soluciones parciales de repartición de renta menor sin leyes estructurales ni autonomía política.

b.- La ausencia de una alianza inter-regionalista y macro-étnica cuyos signos distintivos son: la rebeldía de los territorios con liderazgos contenciosos, pliego de demandas parciales, actos de sabotaje y movilización, represión y tregua, negociaciones, firma de acuerdos con beneficios parciales e integración de líderes a las estructuras de poder - alcaldías, postulaciones al parlamento -, incluyendo a veces el olvido del discurso pro autonomía territorial.

\footnotetext{
${ }^{2}$ A junio del 2017 el congreso había aprobado la elección de gobernadores regionales, pero no concordaba la fecha de su realización ni concordaba el mejoramiento del proceso de traspaso de competencias.
} 


\section{Reflexiones finales}

Para explicar la fuerte pervivencia de la lógica centralista en Chile hay que aceptar que los avances alcanzados en el nivel de desarrollo de Chile como su "estabilidad", superación de la pobreza a niveles del $15 \%^{3}$, contribuyen a configurar la doctrina de no-reforma en las élites dominantes, en la que conviven una amplia legitimidad de la visión centralista junto con una concepción homogénea del Estado en Chile. Esto lleva a diferentes gobiernos a combinar represión-cooptación, como modelo para evitar una transformación política mayor, de corte federalista.

El modelo político tiene disidentes de izquierda federalista (VALENZUELA Y ORTIZ, 2017) empujados por los movimientos territoriales (norte por renta minera, sur por regalías de zonas extremas y el mapuche por autonomía), los que logran en la coyuntura crítica de las protestas sociales 2011-2013 articular una propuesta descentralizadora única en el segundo gobierno de Bachelet.

Los movimientos regionalistas se tensionan entre sus corrientes "reivindicacionistas" mejoras, regalías, nuevas transferencias - y las "autonomistas" que demandan niveles de autogobierno, dominando a las primeras, que son cooptables con soluciones económicas parciales. Los líderes regionalistas son cooptados por partidos nacionales ante la fragmentación del regionalismo y la ausencia de un partido nacional explícitamente regionalista en su agenda.

El uso del nacionalismo ha servido para acusar intentos cesionistas y aislar la demanda regional, con medidas de integración cultural y homogenización. El presidencialismo exacerbado y un modelo electoral híper mayoritario - binominal - acentúa el rechazo de los parlamentarios a ceder al poder ante entes regionales autónomos (mantención del clientelismo y el brokerage).

En los momentos críticos se anuncian reformas que luego no se realizan (cinismo programático). Por otra parte, la ausencia de partidos regionales lleva a la localización y explosión social y callejera de los conflictos. La escasez de alianza entre los distintos movimientos mapuches, alimentada también por la falta de posibilidades de crear partidos y/o plataformas electorales comunales o regionales, ha restado la posibilidad de contar con mayor poder político.

En contraposición con los tradicionales partidos de la derecha y la centro-izquierda socialdemócrata del PPD y del Partido Socialista, han surgido dos expresiones cuestionadoras del modelo, las cuales bregan por mayores transformaciones y autonomía regional. Estas nuevas tendencias políticas están representadas por: a.- el Frente Amplio de agrupaciones de izquierda juvenil que reclaman más educación pública y mayor democratización social y económica, y b.grupos regionalistas de diverso cuño (Federación Regionalista Verde, Partido País en Concepción, Partido Walmapuwen de mapuches en Araucanía) quienes buscan agruparse para recrear un actor sociopolítico por la policentralidad y el empoderamiento socio-económico regional, con autonomía para explorar modelos neodesarrollistas en los territorios.

En ambos casos, conforman iniciativas fuertemente críticas a lo existente, cuyas posibilidades de acción concreta y obtención de resultados debe concitar la atención y el seguimiento en análisis futuros en un contexto mundial, latinoamericano y chileno de reconfiguración de fuerzas políticas.

\section{Bibliografía}

AI CAMP, R. (2000). La política en México, Editorial Siglo XXI, México.

\footnotetext{
${ }^{3}$ Encuesta de Estrateficación Social 2016.
} 
ALCÁNTARA, M. (1997). El análisis de los diputados latinoamericanos en el contexto de los estudios sobre la clase política, en Revista América Latina Hoy, 16, enero.

ALCÁNTARA, M. (2003). Las Tipologías y funciones de los partidos políticos, en VARIOS AUTORES, Curso de Partidos Políticos, AKAL, Madrid.

BAHAMONDE, M. (1977). El caudillo de Copiapó, Editorial Nacimiento, Santiago, Chile.

BELL, A. (2010). Regionalismo autonomista, Iquique.

BENAVENTE, D. (2008). Descentralización: La Revolución Olvidada, Universidad Católica de Temuco, Temuco, Chile.

BOISIER, S. (1989). Palimpsesto de las regiones como espacios socialmente Construidos, en LAURELLI y ROFMAN, Descentralización del Estado.

CEPAL (2016). Informe Fiscal de América Latina y el Caribe, CEPAL, Santiago, Chile.

COMISIÓN PARA LA DESCENTRALIZACIÓN (2014). Informe Final, SUBDERE, Santiago, Chile.

DAITSMAN, A. (1995). The People Shall Be All: Liberal rebellion and popular mobilization in Chile 1830.1860, Thesis Ph.D., University of Wisconsin-Madison, EE.UU.

ENCICLOPEDIA CHILENA (1972), Biblioteca Nacional, Santiago, Chile.

ESPINOZA, V. (2010). Redes de poder y sociabilidad de la élite política chilena. Los parlamentarios 1990-2005, en Revista Polis, 9.

GANDHI, J.; PRZEWORSKI, A. (2006). Cooperation, cooptation and rebellion under dictatorships, en Economics and politics, 18, Oxford, EE.UU.

GAXIE, D. (1983). Les facteurssociaux de la carrièregouvernementale, en Revue Francaise de sociologie, 24, Francia.

GERSCHEWSKI, J. (2010). The Three Pillars of Stability. Towards an Explanation of the Durabili-ty of Autocratic Regimes in East Asia. Paper prepared for the 106th Annual Meeting of the American Political Science Association (APSA), September 2010, Washington, D.C.

ILLANES, M. A. (1993). El proyecto comunal en Chile (Fragmentos): 1810-1891, en Revista Historia, 27, Instituto de Historia, Pontificia Universidad Católica de Chile, Santiago, Chile.

JOIGNANT, A.; GUELL, P. (ed). (2011). Notables, Tecnócratas y Mandarines, Editorial UDP, Santiago, Chile.

MARIMÁN, J. (2012). Autodeterminación, Editorial LOM, Santiago, Chile.

MARTELli, G.; BENAVENTE, D.; VALENZUELA, E. (2002). El Fantasma Federal en Chile, FESUniversidad de Rancagua, Santiago, Chile.

MESSNER, D. (1996). Latinoamérica hacia la economía mundial: Condiciones para el desarrollo de la competitividad sistémica, Prosur FES, Buenos Aires, Argentina.

MOULIAN, T. (2009). Contradicciones del desarrollo político chileno, 1920-1990, Lom-Arcis, Santiago, Chile.

OCDE (2017). Informe Recomendaciones Fortalecimiento Subnacional para Chile, SUBDERE, Santiago, Chile.

ORTIZ, E.; VALENZUELA, E. (2014). Infante y Matta: entre la disidencia y la cooptación. El fracaso del federalismo en el siglo XIX, en Cuadernos de Historia de la Universidad de Chile, (41), Chile.

SALAZAR, G. (2011). En el nombre del Poder Popular Constituyente, Ediciones LOM, Santiago, Chile.

SALAZAR, G. (2005). Construcción de Estado en Chile (1760-1860): democracia de "Los pueblos" militarismo ciudadano golpismo oligárquico, Editorial Sudamericana Santiago, Chile.

VALENZUELA, A. (1977). Political brokers in Chile: local government in a centralizad polity, Duke University Press, Durham, Inglaterra.

VALENZUELA, E. (1999). Alegato Histórico Regionalista, Editorial Sur, Santiago, Chile. 
VALENZUELA, E. (2007). Presicracia centralista en Chile: impuesta por la dictadura derechista y administrada por la centroizquierda paternalista, en CARRIÓN, F., Descentralización en Ecuador: opciones comparadas, FLACSO, Quito, Ecuador.

VALENZUELA, E. (2015). El modelo dual incremental de regionalización en Chile, en Revista Iberoamericana de Estudios Municipales, 6 (11), Chile.

VALENZUELA, E.; ORTIZ, E (2017). La herencia centralista de la izquierda chilena y la irrupción de un progresismo regionalista autonomista, en Revista Izquierdas, 33, mayo, Chile.

VÉLIZ, C. (1984). La tradición centralista de América Latina, Editorial Ariel, Barcelona, España.

VON HALDENWANG, C. (1990). Hacia un concepto politológico de la Descentralización del Estado en América Latina, en Revista EURE, XVI (50), Santiago, Chile. 